$29^{\text {th }}$ International symposium on the Scientific Basis for Nuclear Waste Management, September 12-16, Ghent, Belgium

\title{
Radiation-induced decomposition of $\mathrm{U}(\mathrm{VI})$ alteration phases of $\mathrm{UO}_{2}$
}

MOL. 20051025.0225

\author{
Satoshi Utsunomiya and Rodney C. Ewing
}

Department of Geological Sciences, University of Michigan, Ann Arbor, MI 48109-1063, USA

\begin{abstract}
$\mathrm{U}^{6+}$-phases are common alteration products of spent nuclear fuel under oxidizing conditions, and they may potentially incorporate actinides, such as long-lived ${ }^{239} \mathrm{Pu}$ and ${ }^{237} \mathrm{~Np}$, delaying their transport to the biosphere. In order to evaluate the ballistic effects of $\alpha$-decay events on the stability of the $U^{6+}$-phases, we report, for the first time, the results of ion beam irradiations ( 1.0 $\mathrm{MeV} \mathrm{Kr}^{2+}$ ) for six different structures of $\mathrm{U}^{6+}$-phases: uranophane, kasolite, boltwoodite, saleeite, carnotite, and liebigite. The target uranyl-minerals were characterized by powder X-ray diffraction and identification confirmed by SAED (selected area electron diffraction) in TEM (transmission electron microscopy). The TEM observation revealed no initial contamination of uraninite in these $\mathrm{U}^{6+}$ phases. All of the samples were irradiated with in situ TEM observation using $1.0 \mathrm{MeV} \mathrm{Kr}^{2+}$ in the IVEM (intermediate-voltage electron microscope) at the IVEMTandem Facility of Argonne National Laboratory. The ion flux was $6.3 \times 10^{11}$ ions $/ \mathrm{cm}^{2} / \mathrm{sec}$. The specimen temperatures during irradiation were 298 and $673 \mathrm{~K}$, respectively. The $\mathrm{Kr}^{2+}$-irradiation decomposed the $\mathrm{U}^{6+}$-phases to nanocrystals of $\mathrm{UO}_{2}$ at doses as low as $0.006 \mathrm{dpa}$. The cumulative doses for the pure $\mathrm{U}^{6+}$-phases, e.g., uranophane, at 0.1 and 1 million years (m.y.) are calculated to be 0.009 and $0.09 \mathrm{dpa}$ using SRIM2003. However, with the incorporation of $1 \mathrm{wt} . \%{ }^{239} \mathrm{Pu}$, the calculated doses reach 0.27 and $\sim 1.00 \mathrm{dpa}$ in ten thousand and one hundred thousand years, respectively.

Under oxidizing conditions, multiple cycles of radiation-induced decomposition to $\mathrm{UO}_{2}$ followed by alteration to $\mathrm{U}^{6+}$-phases should be further investigated to determine the fate of trace elements that may have been incorporated in the $\mathrm{U}^{6+}$-phases.
\end{abstract}

\section{Introduction}

Spent nuclear fuel consists primarily of $\mathrm{UO}_{2}(>95 \mathrm{wt} \%)$, and the balance, depending on the burn-up is $\sim 1 \% \mathrm{Pu}, 2-3 \%$ fission product elements and small amounts of other transuranium elements, such as ${ }^{237} \mathrm{~Np}$ (a result of a-decay of ${ }^{241} \mathrm{Am}$ ). Under oxidizing conditions, the $\mathrm{UO}_{2}$ will alter in the presence of water to an assemblage of $\mathrm{U}^{6+}$-phases [1-3]. During the alteration of $\mathrm{UO}_{2}$, radionuclides are released, but some, particularly actinides, such as long-lived ${ }^{239} \mathrm{Pu}$ (half-life $=$ 24,100 years) and ${ }^{237} \mathrm{~Np}$ (half-life $=2.1$ million years), may be re-incorporated into the $\mathrm{U}^{6+}$ phases [4]. Thus, these secondary, $\mathrm{U}^{6+}$ phases become "sinks" for actinides, delaying their transport to the biosphere and lowering their contribution to the calculated doses in performance assessments of geologic repositories [5,6].

Recently, there has been an increased effort to understand the paragenesis of the $\mathrm{U}^{6+}$ alteration phases of $\mathrm{UO}_{2}[7]$ and their stabilities [8] in order to better understand their role in controlling the mobility of radionuclides released during the corrosion of $\mathrm{UO}_{2}$ [9]. The major focus of recent experimental studies has been on the incorporation of very long-lived actinides, such as ${ }^{237} \mathrm{~Np}$ (half-life $=2.1$ million years), into $\mathrm{U}^{6+}$-phases [10-13], because ${ }^{237} \mathrm{~Np}$ is a major contributor to calculated dose at long times for repositories experiencing oxidizing conditions. 
$29^{\text {th }}$ International symposium on the Scientific Basis for Nuclear Waste Management, September 12-16, Ghent, Belgium

However, radiation damage by $\alpha$-decay of actinides causes atomic displacements that lead to amorphization [14] and radiation-enhanced diffusion of trace elements, similar to the radiationenhanced loss of fission product elements in $\mathrm{UO}_{2}$ [15]. Although the $\alpha$-particles dissipate most of their energy by electronic interactions, causing a minimal amount of radiation-enhanced diffusion due to the limited number of atomic displacements [16], the $\alpha$-recoil nucleus dissipates most of its energy by ballistic interactions that can cause more than 1,000 atomic displacements for a single $\alpha$-decay event. While there has been considerable effort devoted to studying radiation effects in spent nuclear fuel [17] and nuclear waste forms [14,18], there has been almost no investigation of the effect of radiation on the corrosion products of $\mathrm{UO}_{2}$. During the first several hundred years after disposal, the radiation field is dominated by the highly ionizing $\beta$ - and $\gamma$-radiation with doses between $10^{8}$ to $10^{6} \mathrm{~Gy} / \mathrm{y}$ [19]. The effects of ionizing radiation on uranophane were previously investigated using a $200 \mathrm{keV}$ electron beam over 95 to $573 \mathrm{~K}$ [20]. The radiation doses required to cause amorphization varied slightly with the composition of the uranophane ( $\mathrm{Sr}$ and Eu were substituted for $\mathrm{Ca}$ ) but were generally in the range $10^{10} \mathrm{~Gy}$. The dose required for amorphization increased by one order of magnitude $\left(10^{11} \mathrm{~Gy}\right)$ above $413 \mathrm{~K}$ due to the loss of structural water. These cumulative doses and dose rates in the experiment are much higher (by three orders of magnitude and seven to ten orders of magnitude, respectively) than that experienced by spent nuclear fuel; hence, ionizing radiation is not expected to have a significant effect on the $\mathrm{U}^{6+}$-phases that form on the surfaces of corroded nuclear fuel. However, beyond several hundred years, the principal source of radiation is from $\alpha$-decay events in the actinide decay chains. For the $\mathrm{U}^{6+}$-phases formed on spent nuclear fuel the accumulated doses are dominated by the $\alpha$-decay of ${ }^{238} \mathrm{U},{ }^{235} \mathrm{U}$, and minor concentrations of ${ }^{239} \mathrm{Pu}$ and ${ }^{237} \mathrm{~Np}$. The recoil nucleus in an $\alpha$-decay event has an energy of $\sim 0.1 \mathrm{MeV}$ and produces approximately 1,200 Frenkel pair defects along a stopping distance of 30 to $50 \mathrm{~nm}$, creating a displacement cascade about $5 \mathrm{~nm}$ in size. The density of energy deposited into the crystal structure by an $\alpha$-recoil cascade is very high, up to $1 \mathrm{eV} /$ atom, and energy-deposition occurs over a very short time, $<10^{\circ}$ ${ }^{12} \mathrm{~s}$. The cumulative doses for the pure $\mathrm{U}^{6+}$-phases, e.g., uranophane, at 0.1 and $1 \mathrm{~m} . \mathrm{y}$. are calculated, using SRIM2003 [21], to be 0.009 and 0.09 dpa (displacements per atom). However, with the incorporation of $1 \mathrm{wt} . \%{ }^{239} \mathrm{Pu}$, the doses may reach 0.27 and $\sim 1.00 \mathrm{dpa}$ in ten thousand and one hundred thousand years, respectively. The damage production process can cause the formation of point defects, defect clusters, amorphous domains, metastable phases, and elemental segregation into bubbles, surfaces and grain boundaries. These ballistic interactions can be simulated by charged-particle irradiations, typically with 0.5 to $1.5 \mathrm{MeV} \mathrm{Xe}, \mathrm{Kr}, \mathrm{Ar}$ and $\mathrm{Pb}$ ions, observed in situ by transmission electron microscopy [14,22]. Consistent results have been obtained in comparison to results from actinide-doping experiments [23].

In this study, we have used $1.0 \mathrm{MeV} \mathrm{Kr}^{2+}$ irradiations to simulate the ballistic interactions of the $\alpha$-recoil nucleus with different $\mathrm{U}^{6+}$ - phases listed below:

$$
\begin{aligned}
& \text { uranophane, } \mathrm{Ca}\left[\left(\mathrm{UO}_{2}\right)\left(\mathrm{SiO}_{3} \mathrm{OH}\right)\right]_{2}\left(\mathrm{H}_{2} \mathrm{O}\right)_{5} \\
& \text { boltwoodite, } \mathrm{K}\left[\left(\mathrm{UO}_{2}\right)\left(\mathrm{SiO}_{3} \mathrm{OH}\right)\right]\left(\mathrm{H}_{2} \mathrm{O}\right)_{1.5} \\
& \text { kasolite, } \mathrm{Pb}\left[\left(\mathrm{UO}_{2}\right)\left(\mathrm{SiO}_{4}\right)\right]\left(\mathrm{H}_{2} \mathrm{O}\right) \\
& \text { saléeite, } \mathrm{Mg}\left[\left(\mathrm{UO}_{2}\right)\left(\mathrm{PO}_{4}\right)\right]_{2}\left(\mathrm{H}_{2} \mathrm{O}\right)_{10} \\
& \text { carnotite, } \mathrm{K}_{2}\left(\mathrm{UO}_{2}\right)_{2}\left(\mathrm{~V}_{2} \mathrm{O}_{8}\right)\left(\mathrm{H}_{2} \mathrm{O}\right)_{3} \\
& \text { liebigite, } \mathrm{Ca}_{2}\left[\left(\mathrm{UO}_{2}\right)\left(\mathrm{CO}_{3}\right)_{3}\right]\left(\mathrm{H}_{2} \mathrm{O}\right)_{11}
\end{aligned}
$$

These $\mathrm{U}^{6+}$-phases are typical of the minerals that occur as the secondary, uranyl-alteration phases that form under oxidizing conditions at uranium ore deposits. Uranophane and boltwoodite have been observed to form in laboratory studies of the alternation of spent nuclear fuel $[2,24]$. The 
$29^{\text {th }}$ International symposium on the Scientific Basis for Nuclear Waste Management, September 12-16, Ghent, Belgium

other phases were selected so as to have a variety of uranyl structure types (Figure 1). These $\mathrm{U}^{6+}$-phases generally form sheets of edge- and corner-sharing $\mathrm{U}$-coordination polyhedra with the larger, inter-layer cations, such as $\mathrm{Ca}$ or $\mathrm{K}$, located between the sheets of U-coordination polyhedra $[25,26]$. Liebigite is not a sheet structure, forming instead isolated clusters (Figure 1d). In Figure 1, we also include the schematic of the three-dimensional structure of $\mathrm{UO}_{2}$, a fluorite structure-type in which $\mathrm{U}^{4+}$ is in cubic coordination, and one-half of the cubic sites are empty.

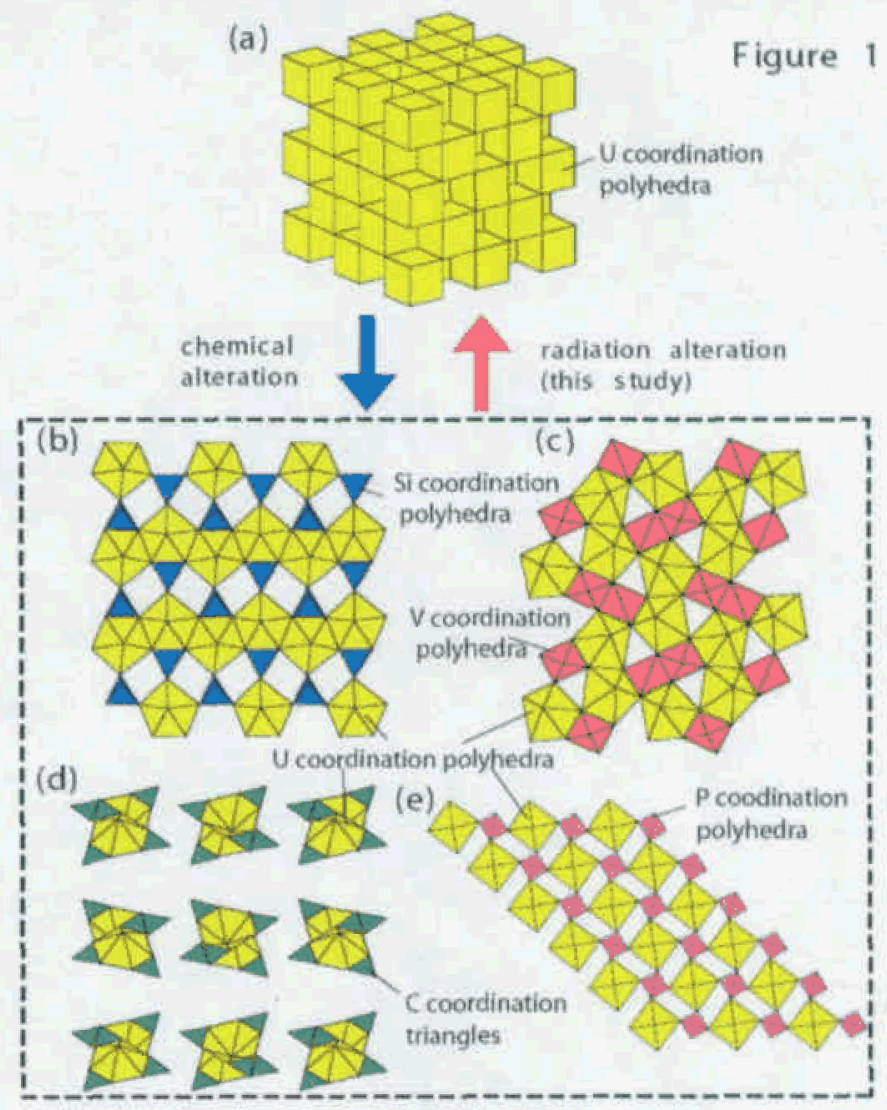

Fig. 1. Schematic diagrams of the anion topologies of the uranyl-minerals of this study. (a) Uraninite. (b) Uranyl silicates including boltwoodite, uranophane and kasolite viewed along the a-axis. (c) Uranyl vanadate, carnotite along a-axis. (d) Uranyl carbonate, liebigite along c-axis. (e) Uranyl phosphate, saléeite along b-axis.

\section{Experimental Techniques}

Target materials of secondary uranyl-minerals for the present irradiation experiments were characterized by powder X-ray diffraction analysis (XRD) to minimize the contamination by other phases and also confirmed by a SAED pattern in TEM. All of the $x$-ray diffraction peaks belonged to the pure uranyl-phase that was identified in each XRD pattern, except that the uranophane contained a small amount of sklodowskite which has a similar structure as uranophane, but with the substitution of $\mathrm{Mg}$ for $\mathrm{Ca}$. Because of the small amount of the carnotite sample, XRD analysis could not be done. The TEM observation revealed no contamination of uraninite in any of the target materials. Liebigite was unstable under minimum electron beam 
$29^{\text {th }}$ International symposium on the Scientific Basis for Nuclear Waste Management, September 12-16, Ghent, Belgium

irradiation. Thus, the SAED of liebigite is not shown. TEM characterization was completed using a JEOL $2010 \mathrm{~F}$. The acceleration voltage is $200 \mathrm{kV}$ and the spherical aberration coefficient is $1.0 \mathrm{~mm}$. Scanning TEM imaging and elemental mapping were also completed using the same instrument with $0.5 \mathrm{~nm}$ of the spot size. A drift correction mode was used during the acquisition of data. All of the samples were irradiated with in situ TEM observation using $1.0 \mathrm{MeV} \mathrm{Kr}^{2+}$ in the IVEM (intermediate-voltage electron microscope) at the IVEM-Tandem Facility of Argonne National Laboratory. The ion flux was 6.3 _ $10^{11}$ ions $/ \mathrm{cm}^{2} / \mathrm{sec}$. The specimen temperatures during irradiation were 298 and $673 \mathrm{~K}$, respectively. The structural transition was observed by SAED. The electron beam was off during the ion irradiation, and only used for short intervals during the ion irradiation. In this way, the effect of electron beam was minimized and negligible. However, to estimate the ionizing effects on these uranyl-phases, we have also completed electron irradiation experiments on these phases. Schoepite, $\left[\left(\mathrm{UO}_{2}\right)_{8} \mathrm{O}_{2}(\mathrm{OH})_{12}\right]\left(\mathrm{H}_{2} \mathrm{O}\right)_{12}$ was additionally tested in the e-beam irradiation experiment. The experiments were conducted using a transmission electron microscope with electron fluxes of $\sim 8-33 \_10^{17}\left(\mathrm{e}-/ \mathrm{cm}^{2} / \mathrm{sec}\right)$ at room temperature. Ion fluence was converted to dpa using SRIM2000 [21]. The displacement energies, $E_{d}$, were assumed to be $40 \mathrm{eV}$ for $\mathrm{U}$ [14], 23 for $\mathrm{P}$ and $\mathrm{Si}$ [14], $28 \mathrm{eV}$ for O [14], $10 \mathrm{eV}$ for $\mathrm{H}$ [21], $20 \mathrm{eV}$ for $\mathrm{C}$ [21] and $25 \mathrm{eV}$ for interlayer cations and $\mathrm{V}$ [21].

\section{Results and discussion}

\section{The effect of ionizing radiation}

Figure 2 shows SAED of transition during the e-beam irradiation experiments on the uranyl-phases. During the irradiation, boltwoodite, saléeite, and carnotite became amorphous at doses of $1-4 \_10^{10}$ gray (Gy), while the amorphization dose $\left(D_{c}\right)$ of kasolite, 50_10 10 Gy, was about an order of magnitude higher than that of boltwoodite. This high $\mathrm{D}_{c}$ for kasolite is consistent with the hypothesis that the $\mathrm{D}_{c}$ increases as the mass of the inter-layer cation increases. Only amorphization, rather than chemical decomposition, occurred in boltwoodite, saléeite and carnotite, even at doses as high as $80 \_10^{10} \mathrm{~Gy}$. In contrast, uraninite nanocrystallites began to form with a random orientation at $\sim 43 \_10^{10} \mathrm{~Gy}$ in liebigite which had already become amorphous prior to irradiation in the vacuum of the TEM. For schoepite, the $D_{c}$ was only $0.51 \_10^{10} \mathrm{~Gy}$, and randomly oriented uraninite nanocrystallites formed at $7.8 \_10^{10} \mathrm{~Gy}$ which is approximately the same dose as compared with the $\mathrm{D}_{\mathrm{c}} \mathrm{s}$ for the other $\mathrm{U}^{6+}$-phases. Because the predicted cumulative dose by the ionizing radiation in spent nuclear fuel is $\sim 10^{7}-10^{8}$ Gy during the first $10^{2-3}$ years after discharge, an additional contribution of ionizing radiation dose by _decay events is needed in order to induce amorphization in these $\mathrm{U}^{6+}$-phases.

\section{The effect of heavy ion irradiation}

During 1.0 MeV Kr${ }^{2+}$ irradiation of uranophane, both at room temperature and $673 \mathrm{~K}$, some areas decomposed at an ion fluence of $1.25 \times 10^{13} \mathrm{ions} / \mathrm{cm}^{2}(0.014 \mathrm{dpa})$. Diffraction maxima in SAED patterns became diffuse and disappeared, but a pattern of diffraction rings appeared (Fig. 3 ). Irradiation at elevated temperature $(673 \mathrm{~K})$ also showed the transition to ring patterns in the SAED. All of the radiation-induced ring patterns including those revealed at elevated temperature were identified as uraninite (in Fig. 3) without any evidence of other crystalline phases. The diffraction pattern of kasolite revealed some intense diffraction maxima that indicate 
$29^{\text {th }}$ International symposium on the Scientific Basis for Nuclear Waste Management, September 12-16, Ghent, Belgium

a preferred orientation for the crystallites or a large crystalline size, $>100 \mathrm{~nm}$, but the pattern was still identified as uraninite. There was some variation in the nucleation of uraninite nanocrystals as a function of fluence even in the same phase at different positions within sample. Most of the $\mathrm{U}^{6+}$-phase decomposed to polycrystals of uraninite at $\sim 10^{13}-10^{14} \mathrm{ion} / \mathrm{cm}^{2}$. The range of the ion fluences was equivalent to $0.006-0.2 \mathrm{dpa}$. The minimum dose for the formation of nanocrystals of $\mathrm{UO}_{2}$ in uranophane was $0.006 \mathrm{dpa}$. Because the radiation-induced structural transformation was most clearly recognized in boltwoodite, the results for boltwoodite are given in detail.

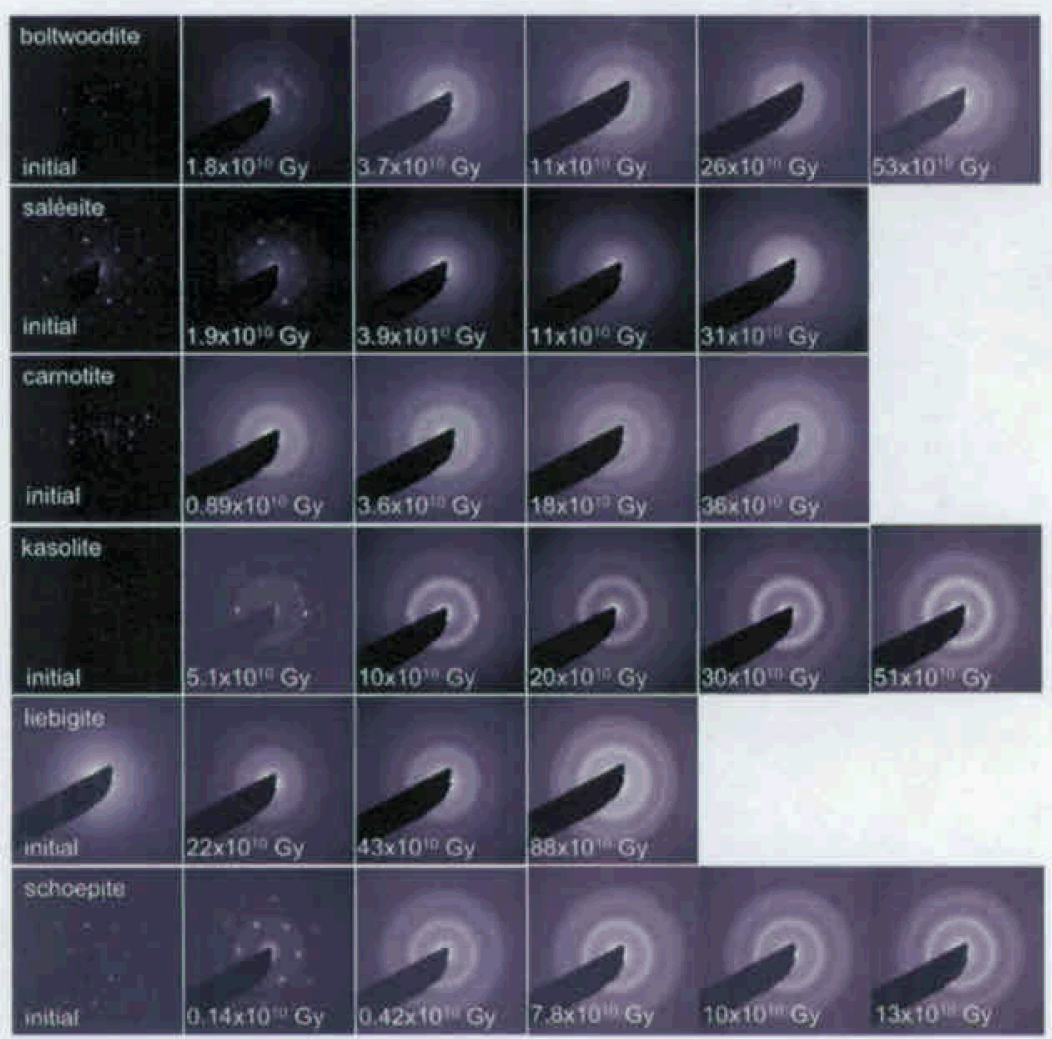

Fig. 2. The SAEDs of transition in the uranvl-phases as a function of the cumulative ionizing dose.
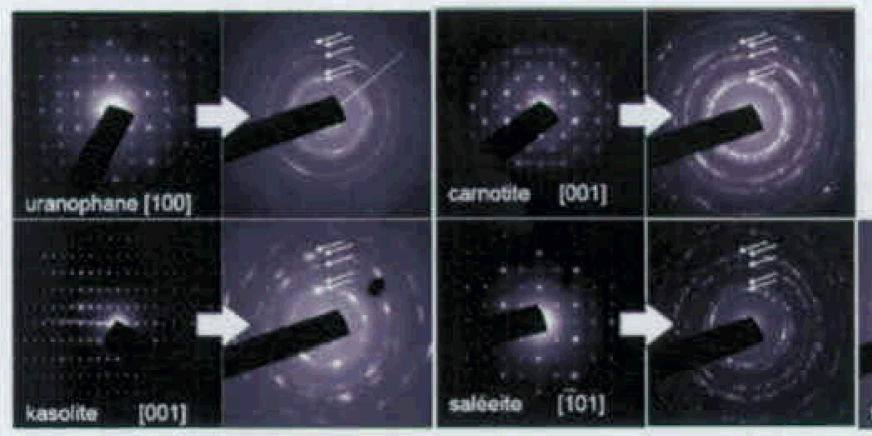

Fig. 3. The SAED patterns before and after 1.0 uranophane $0 \rightarrow 0.77$ dpa. kasolite, $0 \rightarrow 2.2 \mathrm{dp}$ after $0.85 \mathrm{dpa}$. The white arrows indicate the po nolvervstalline uraninite.

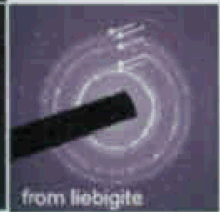


$29^{\text {th }}$ International symposium on the Scientific Basis for Nuclear Waste Management, September 12-16, Ghent, Belgium

Figure 4a shows the radiation-induced transition as evidenced in the SAED pattern in boltwoodite from 0 to $1.37 \mathrm{dpa}$ on $\mathrm{Kr}^{2+}$-irradiation at $298 \mathrm{~K}$. The boltwoodite retained a euhedral, needle-like crystal form after irradiation; however, the entire crystal was completely converted to an aggregate of uraninite nanocrystals at the dose of $1.37 \mathrm{dpa}$ (Fig. 4b). High-resolution TEM (HRTEM) images revealed that the nanocrystals vary in size: $>20 \mathrm{~nm}$ (Fig. $4 \mathrm{c}$ ) and the smallest was $<5 \mathrm{~nm}$ (Fig. 4d). In addition, amorphous domains were present at the boundaries of uraninite nanocrystals (Fig. 4d). Following the formation of uraninite nanocrystals from uranyl alteration phases, the other cations; $\mathrm{Si}$ and $\mathrm{K}$, should be present within amorphous domains. The sequence of events for the formation of the nanocrystals of uraninite may be described as: (i) Decomposition of uranyl-minerals to $\mathrm{UO}_{2}$ in the displacement cascades created by ion irradiation. (ii) Rapid nucleation of uraninite nanocrystals in the highly disordered "melt-like" displacement cascade. The nano-scale size of the recrystallized uraninite is probably due to rapid "quenching" within the cascades. Indeed, irradiation-induced nanocrystallization is frequently reported to be associated with decomposition and nucleation processes [28].

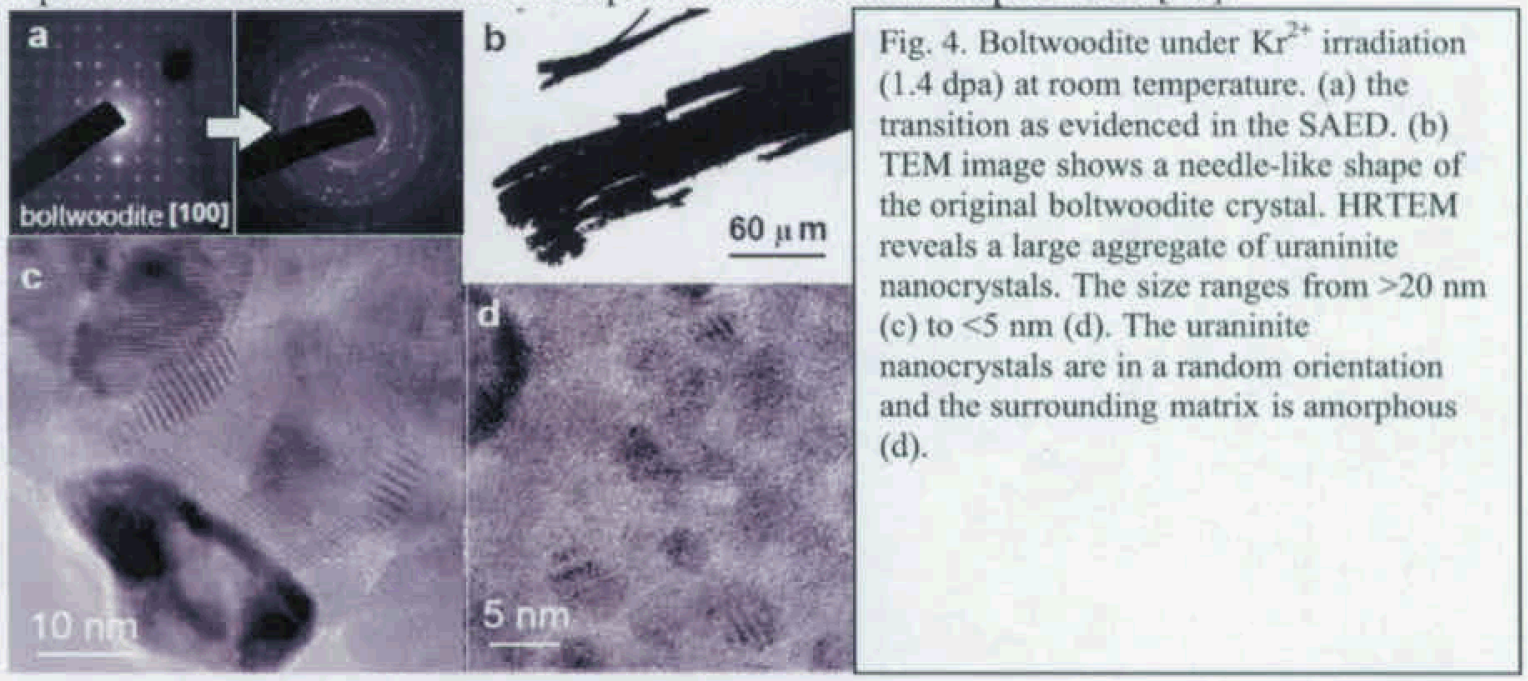

Clearly, the nanocrystals of uraninite were produced by ion irradiation and decomposition of these uranyl-minerals. However, there are differences in the conditions between the ion irradiation experiments and $\alpha$-decay events. The dose rate during the ion irradiation experiments is $\sim 10^{11}$ times higher than that from $\alpha$-decay events experienced by naturally occurring $\mathrm{U}^{6+}$ phases. The higher dose rate leads to greater cascade overlap because there is minimum opportunity for relaxation and recovery of defects formed by the cascade. The higher dose rate usually results in an increase in the critical amorphization temperature for materials, $T_{c}$, the temperature above which the amorphization does not occur due to thermal annealing [29]. Changes in the energy and species of ion are also considered to result only in shifts of the amorphization dose and $T_{c}[14,28]$. Also, the incident ion species used in the present experiments were $\mathrm{Kr}^{2+}$ at energy of $1.0 \mathrm{MeV}$; whereas, in an $\alpha$-decay event, the recoil nuclei are heavier and have a lower energy. As an example, the recoil nucleus of ${ }^{239} \mathrm{Pu}$ is ${ }^{235} \mathrm{U}$ with the energy of $86 \mathrm{keV}$ [14]. However, these differences are accounted for by the conversion of the ion fluences to displacements per atom using SRIM [21], allowing the comparison of the two different types of irradiations. Thus, we expect that the ion-beam irradiation results are a reasonable simulation of the ballistic interactions of $\alpha$-recoil nuclei that have led to the formation of nanocrystals of $\mathrm{UO}_{2}$. 
$29^{\text {th }}$ International symposium on the Scientific Basis for Nuclear Waste Management, September 12-16, Ghent, Belgium

Uraninites from natural uranium deposits and $\mathrm{U}^{6+}$-alteration products formed under oxidizing conditions were also examined to see if there was evidence for the decomposition and formation of nanocrystals of $\mathrm{UO}_{2}$, similar to those observed in the ion irradiation experiments. Samples from the 2.0 b.y.-old natural fission reactor at Oklo, Gabon [26] was examined. Using TEM, some uraninites were found as large single crystals at the micron scale, but others were present as aggregates of nanocrystals. The presence of $\mathrm{Si}$ and $\mathrm{Mg}$ was also revealed by EDS. The HRTEM image revealed aggregates of nanocrystalline uraninite with the amorphous matrix containing Si at the grain boundaries, a texture similar to that observed in the ion irradiationinduced nanocrystals of uraninite. Although it is possible that the uraninite precipitated as a secondary phase under reducing conditions, coffinite, $\mathrm{USiO}_{4} n \mathrm{H}_{2} \mathrm{O}$, is stable in solutions containing $\mathrm{Si}$; thus, the formation of coffinite is the expected phase in these samples [30]. However, $\mathrm{Si}$ is present in the amorphous matrix, with no evidence of the formation of coffinite, and the uraninite nanocrystals are randomly oriented, forming high-angle grain boundaries. In addition, although an aluminosilicate was observed adjacent to the aggregates of uraninite, the uraninite region was $\mathrm{Al}$-free, suggesting that this $\mathrm{Si}$ was not associated with the altering solution that caused the formation of the aluminosilicate. Although it is still possible that these uraninite nanocrystals formed by another unkown process, their presence in the Oklo sample is at least consistent with the radiation-induced decomposition of uranyl-minerals to $\mathrm{UO}_{2}$ as observed in the ion beam irradiation experiments.

\section{Conclusions}

Based on the results of the ion irradiation of $\mathrm{U}^{6+}$-phases, the recoil nucleus of an $\alpha$-decay event of actinides in secondary uranyl minerals causes decomposition and nano-scale formation of $\mathrm{UO}_{2}$. The nanocrystals of $\mathrm{UO}_{2}$ form at doses as low as $0.006 \mathrm{dpa}$, which is slightly less than the accumulated dose in pure $\mathrm{U}^{6+}$ phases due to self $\alpha$-decay after 100,000 years, $0.009 \mathrm{dpa}$. However, the addition of $1 \mathrm{wt} . \%{ }^{239} \mathrm{Pu}$ leads to an increase in dose to $0.27 \mathrm{dpa}$ in 10,000 years, well in excess of the dose required for radiation-induced decomposition of the $\mathrm{U}^{6+}$-phases. Thus, one expects, in altered uraninite older than 10,000 years, multiple cycles of radiation-induced decomposition of $\mathrm{U}^{6+}$-phases to nanocrystals of $\mathrm{UO}_{2}$, followed by re-alteration back to $\mathrm{U}^{6+}$ phases under oxidizing conditions. During these repeated cycles of radiation-damage (i.e., cascade quenching and decomposition to $\mathrm{UO}_{2}$ ) and alteration back to $\mathrm{U}^{6+}$-phases, trace elements may be lost by this nano-scale, zone-refining process. Due to the extremely small size and high surface area of the $\mathrm{UO}_{2}$ nanoparticles, oxidation and alteration back to $\mathrm{U}^{6+}$-phases will generally be rapid. This may explain the rather high purity, relative to trace elements, of the uranyl alteration phases observed in nature. This is also a process by which radionuclides incorporated in $\mathrm{U}^{6+}$-phases may be released and available for transport in the geosphere.

\section{Acknowledgements}

The authors thank the staff of the IVEM-Tandem Facility at Argonne National Laboratory for assistance during the ion irradiation experiments. S.U. thanks J. F. Mansfield and C. J. Wouchope of the Electron Microbeam Analysis Laboratory at University of Michigan. This work was supported by the Office of Science and Technology and International (OSTI) of the Office of Civilian Radioactive Waste Management (DE-FE28-04RW12254). 
$29^{\text {th }}$ International symposium on the Scientific Basis for Nuclear Waste Management, September 12-16, Ghent, Belgium

\section{References}

[1]. R. J. Finch, R. C. Ewing, J. Nucl. Mater. 190, 133 (1992).

[2]. D. J. Wronkiewicz, J. K. Bates, T. J. Gerding, E. Veleckis, B. S. Tani, J. Nucl. Mater. 190, 107 (1992).

[3]. R. J. Finch, T. Murakami, in Uranium-Mineralogy, Geochemistry and the Environment, P. C. Burns, R. J. Finch, Eds. Rev. Miner. 38, 91 (1999).

[4]. P. C. Burns, R. C. Ewing, M. L. Miller, J. Nucl. Mater. 245, 1 (1997).

[5]. E. Curti, Coprecipitation of radionuclides: basic concepts, literature review and first applications, Paul Scherrer Institut, Bericht Nr. 97-10. p107 (1997).

[6]. Y. Chen, Computers \& Geoscience, 29, 385 (2003).

[7]. D. Wronkiewiecz, E. Buck, in Uranium -Mineralogy, Geochemistry and the Environment, P. C. Burns, R. J. Finch, Eds. Rev. Miner. 38, 475 (1999).

[8]. F. Chen, R. C. Ewing, S. B. Clark, Am. Mineral. 84, 650 (1999).

[9]. W. M. Murphy, R. B. Codell, Mater. Res. Soc. Proc. 556, 551 (1999).

[10]. E. Buck, R. J. Finch, P. A. Finn, J. K. Bates, Mater. Res. Soc. Proc. 506, 87 (1998).

[11]. P. C. Burns, K. M. Deely, S. Skanthakumar, Radiochim. Acta 92, 151 (2004).

[12]. M. Douglas, S. B. Clark, J. I. Friese, B. W. Arey, E. C. Buck, B. D. Hanson, S. Utsunomiya, R. C. Ewing, Radiochim. Acta 93, 265 (2005).

[13]. M. Douglas, S. B. Clark, J. I. Friese, B. W. Arey, E. C. Buck, B. D. Hanson, Environ. Sci. Technol. in review.

[14]. W. J. Weber, et al., J. Mater. Res. 13, 1434 (1998).

[15]. H. Matzke, Rad. Eff. Def. Solid. 64, 3 (1982).

[16]. L. Desgranges, M. Ripert, J. P. Piron, H. Kodja, J. P. Gallier, J. Nucl. Mater. 321, 324 (2003).

[17]. H. Matzke, L. M. Wang, L.M. J. Nucl. Mater. 231, 155 (1996).

[18]. R. C. Ewing, W. J. Weber, J. Lian, J. Appl. Phys. 95, 5949 (2004).

[19]. D. W. Shoesmith, J. Nucl. Mater. 282, 1 (2000).

[20]. S. Utsunomiya, L. M. Wang, M. Douglas, S. B. Clark, R. C. Ewing, Am. Min. 88, 159 (2003).

[21]. J. F. Ziegler, J. P. Biersack, U. Littmark, The stopping and range of ions in solids (Pergamon, New York, 1985).

[22]. L. M. Wang, R. C. Ewing, Mater. Res. Soc. Bull. 17, 38 (1992).

[23]. W. J. Weber, R. C. Ewing, Science 289, 2051 (2000).

[24]. D. J. Wronkiewicz, J. K. Bates, S. F. Wolf, E. C. Buck, J. Nucl. Mater. 238, 78 (1996).

[25]. P. C. Burns, in Uranium -Mineralogy, Geochemistry and the Environment, P. C. Burns, R. J. Finch, Eds. Rev. Miner. 38, 23 (1999).

[26]. P. C. Burns, M. L. Miller, R. C. Ewing, Can. Mineral. 34, 845 (1996).

[27]. K. A. Jensen, R. C. Ewing, GSA Bull. 113, 32 (2001).

[28]. L. M. Wang, et al., Mater. Sci. Eng. A 286, 72 (2000).

[29]. S. X. Wang, L. M. Wang, R. C. Ewing, Phys. Rev. B 63, 024105, (2000).

[30]. J. Janeczek, R. C. Ewing, J. Nucl. Mater. 190, 157-173 (1992). 